\title{
Erratum to: Volatiles from Intact and Lygus-Damaged Erigeron annuus (L.) Pers. are Highly Attractive to Ovipositing Lygus and its Parasitoid Peristenus relictus Ruthe
}

Sean T. Halloran • Kerry E. Mauck • Shelby J. Fleischer • James H. Tumlinson

Published online: 13 October 2013

(C) Springer Science+Business Media New York 2013

Erratum to: J Chem Ecol (2013)

DOI 10.1007/s10886-013-0331-y

An author name was inadvertently misspelled in the original publication of this article. The correct spelling is as follows:

Shelby J. Fleischer (replaces Shelby F. Fleisher)

The online version of the original article can be found at http://dx.doi.org/ 10.1007/s10886-013-0331-y. 